\title{
High Dose Chemotherapy and Autologous Peripheral Blood Stem Cell Transplantation for Persistent/Relapsed Ovarian Cancer
}

So Eun Kim, M.D. ${ }^{1}$, Jong Ho Won, M.D. ${ }^{1}$, Hyun Soo Kim, M.D. ${ }^{2}$, Joon Sung Park, M.D. ${ }^{2}$, Chan Kyu Kim, M.D. ${ }^{1}$, Kyu Taeg Lee, M.D. ${ }^{1}$, Sung Kyu Park, M.D. ${ }^{1}$, Seung Ho Baick, M.D. ${ }^{1}$, Dae Sik Hong, M.D. ${ }^{1}$, Hee Sook Park, M.D. ${ }^{1}$ and Hugh Chul Kim, M.D. ${ }^{2}$

Departments of Internal Medicine, ${ }^{1}$ Soon Chun Hyang University College of Medicine, Seoul and ${ }^{2}$ Ajou University College of Medicine, Suwon, Korea

Purpose: High dose chemotherapy (HDC) is increasingly being used for ovarian cancer. Although early studies of autotransplantation for advanced ovarian cancer have been encouraging, most reported series were small, and no randomized trials have been reported. HDC and autologous hematopoietic stem cell transplantation were rarely performed in patients with ovarian cancer in Korea, and no results have been reported with the exception of one case report.

Materials and Methods: We retrospectively analyzed 10 patients with refractory or relapsed ovarian cancer having received $H D C$ and autologous peripheral blood stem cell transplantation (APBSCT), between January 1996 and September 1998, at the Soon Chun Hyang and Ajou University Hospitals.

Results: Ten patients were treated with HDC and APBSCT. Six patients achieved complete response (CR) and 1 a partial response (PR), with a response rate of $70 \%$. Three patients did not respond following mobi-

\section{INTRODUCTION}

Advanced ovarian cancer is the most common cause of death from gynecologic malignancies and the fourth most common cause of cancer deaths in women (1). The frequency of ovarian cancer is $4.2 \%$ of the female primary cancers in Korea (2). Despite an aggressive surgical debulking, followed by cisplatincontaining chemotherapy, only 20 to $30 \%$ of patients with a stage III epithelial ovarian carcinoma will survive longer than 5 years, and for the stage IV disease the 5-year survival is approximately $5 \%(3,4)$. These kinds of tumor are sensitive to first line chemotherapy, with nearly an $80 \%$ complete clinical

Correspondence: Jong Ho Won, Department of Internal Medicine, Soon Chun Hyang University Hospital, 657 Hannam-dong, Yongsan-gu, Seoul 140-743, Korea (Tel) 709-9203, (Fax) 709-9200, (E-mail) jhwon@hosp.sch.ac.kr

Received July 10, 2002, Accepted October 18, 2002 lization chemotherapy, and failed to respond after HDC. The median duration of progression free survival (PFS) and overall survival (OS) were $6(4 \sim 46)$ and $13(3 \sim 50+)$ months, respectively. The median duration of $O S$ of the responders following mobilization chemotherapy was 23 $(8 \sim 50+)$ compared with $12(3 \sim 18)$ months of the nonresponders. With regard to the treatment related toxicity, 8 patients had neutropenic fevers, and bacteremia was documented in 4 . The non-hematological toxicities were never life threatening, and there were no treatment related deaths.

Conclusion: HDC, followed by APBSCT, is well-tolerated patients with refractory or relapsed ovarian cancer, and following mobilization chemotherapy the responders survived longer than the non-responders. (Cancer Research and Treatment 2002;34:439-443)

Key Words: Ovarian neoplasm, High dose chemotherapy, Stem cell transplantation

response (CR) and a $40 \%$ pathological CR. However, the majority of responding patients will subsequently develop chemoresistant recurrence, and subsequently die (5). Increased exposure to cytotoxic drugs was considered a likely means of overcoming resistance and potentially increasing response rates and survival. Increasing the dose intensity has been achieved with high-dose chemotherapy (HDC), combination platinum therapies, intraperitoneal therapy and stem cell-supported highdose chemotherapy. Although clinical trials of double-dose chemotherapy, in advanced ovarian cancer, have not indicated an increase in cure rates, considerable in vitro and in vivo data support the importance of the dose intensity in treating ovarian cancer, including trials of high-dose cisplatin delivered intraperitoneally $(6,7)$. An ovarian carcinoma is a favorable candidate for HDC and autologous hematopoietic stem cell transplantation (AHSCT) for three reasons. Firstly, it is chemosensitive, particularly to alkylating agents, most of which have a hematological toxicity, which can be controlled by AHSCT. Secondly, the dose-response and intensity have been demonstrated with these drugs for this disease. Finally, bone marrow metastases 
are exceptional during the evolution of this cancer, so graft contamination is unlikely (5). The first pilot studies of HDC and AHSCT in ovarian carcinomas were realized in conventional chemotherapy refractory patients, and proved its feasibility and tolerability, with encouraging response rates $(8 \sim 10)$. Although conventional salvage therapy for ovarian cancers produce responses in 15 to $25 \%$ of women with the platinum sensitive disease, the response rates in early trials of autotransplantation have been reported to be as high as $75 \%$ with drug resistant tumors. However, the duration of response is short (average, 6 to 7 months) in patients who receive transplants for the refractory disease. In a recent study, Legros and coworkers reported a 5-year survival rate of $60 \%$ in 53 patients who received autotransplants following completion of the induction therapy for advanced ovarian cancers. Because 5-year survival rates of 20 to $30 \%$ are common, in unselected groups of women with an advanced-stage disease that received standard platinumbased chemotherapy, the study of Legros and colleagues suggests that autotransplantation may be beneficial during the first remission (11). Although early studies of autotransplantation for advanced ovarian cancers have been encouraging, most reported series are small, and no randomized trials have been reported. HDC and AHSCT were rarely performed in patients with ovarian cancer in Korea, and no results have been reported, with the exception of one case report (12).

We analyzed 10 patients with refractory or relapsed ovarian cancer, who had received HDC and autologous peripheral blood stem cell transplantation (APBSCT) at Soon Chun Hyang and Ajou University Hospitals.

\section{MATERIALS AND METHODS}

\section{1) Patients}

Between January 1996 and September 1998, 10 patients with refractory or relapsed epithelial ovarian cancer underwent HDC and APBSCT. Patients with histologically proven epithelial ovarian cancer, with a tumor that was resistant to cisplatin and/or paclitaxel containing chemotherapy, with a performance status less than grade 3, according to the criteria of the ECOG, were eligible for the study. Another eligibility criteria included an age of less than 65 years, no psychiatric disease and adequate end organ function: renal (creatinine clearance 60 $\mathrm{ml} / \mathrm{min}$ ), hepatic (serum bilirubin and transaminase $<1.5$ times normal), cardiac (left ventricular ejection fraction $>50 \%$ ), respiratory (cardiac monoxide diffusion capacity $>50 \%$ of normal) and hematological (WBC count $3.500 / \mathrm{mm}^{3}$, Hb level $>10 \mathrm{~g} / \mathrm{dl}$, platelet count $>100,000 / \mathrm{mm}^{3}$ ). Patients were required to be HIV-negative and free of active infection. Tumor free bone marrow, assessed by bone marrow aspirates and biopsy, was initially required. All patients signed a written consent form.

\section{2) Mobilization and cytoreductive chemotherapy}

For PBSC mobilization, and pretransplant cytoreduction, patients who were refractory to cisplatin received paclitaxel $\left(175 \mathrm{mg} / \mathrm{m}^{2}\right.$ on day 1) and carboplatin $(\mathrm{AUC}=7.5 \mathrm{mg} / \mathrm{ml} / \mathrm{min}$ on day 1) and those who were relapsed and refractory to paclitaxel and cisplatin received ifosfamide $\left(1,000 \mathrm{mg} / \mathrm{m}^{2} / \mathrm{d}\right)$, etoposide $\left(150 \mathrm{mg} / \mathrm{m}^{2} / \mathrm{d}\right)$ and carboplatin $\left(200 \mathrm{mg} / \mathrm{m}^{2} / \mathrm{d}\right)$ on days 1 to 2 (mini ICE regimen). G-CSF was subcutaneously injected at $5 \mu \mathrm{gg} / \mathrm{kg} / \mathrm{day}$ from day 5 until completion of the stem cell harvest. Mesna was given before and on completion of the ifosfamide to prevent hemorrhagic cystitis. All patients received 2 cycles of mobilization chemotherapy.

\section{3) Stem cell collection}

An aphaeresis was performed in all patients using a COBE Spectra cell separator (COBE BCT, Lakewood, CO, USA). The number of mononuclear (MNCs) and CD34+ cells of the collection product were measured immediately after aphaeresis. The cells were subsequently cryopreserved using a programmed freezer. The CD34+ cell concentration was analyzed by two colors flow cytometry, and the number of colony forming unit-granulocyte-macrophage (CFU-GM) colony was calculated after incubation on a methylcellulose medium (MethoCult ${ }^{\mathrm{TM}}$ H4431, Stem Cell Technologies, Vancouver, BC, Canada).

\section{4) HDC and APBSCT}

All the patients received carboplatin $\left(500 \mathrm{mg} / \mathrm{m}^{2} / \mathrm{d}\right)$, etoposide $\left(700 \mathrm{mg} / \mathrm{m}^{2} / \mathrm{d}\right)$ and ifosfamide $\left(3,300 \mathrm{mg} / \mathrm{m}^{2} / \mathrm{d}\right)$ on days 4 , 3 and 2 (ICE regimen). Chemotherapy was administered through a central venous catheter, with hydration and intravenous mesna added to prevent hemorrhagic cystitis. Stem cells were reinfused on day 0 . G-CSF was administered on day 5 , and was continued until the neutrophil count exceeded $1,000 / \mathrm{mm}^{3}$ for 2 consecutive days following aplasia.

\section{5) Supportive care}

All patients received hyperalimentation through a central venous catheter, and were admitted to isolated private rooms or laminar, filtered-air flow, bacterial clean rooms. Transfusions of irradiated blood products were administered for hemoglobin levels less than $8.0 \mathrm{~g} / \mathrm{dl}$ or platelet counts less than $20,000 / \mathrm{mm}^{3}$. All patients received prophylactic fluconazole for fungal infection prophylaxis (200 mg orally twice daily) and acyclovir for herpes virus prophylaxis (400 $\mathrm{mg}$ orally twice daily).

\section{6) Response definition}

A CR was defined as the complete disappearance of all measurable and assessable disease for a minimum of 4 weeks. Furthermore, CA-125 levels were required to be in the normal range $(<35 \mathrm{IU} / \mathrm{ml})$ for patients with ovarian cancer who had elevated pretreatment levels. A partial response (PR) was defined as a $\geq 50 \%$ reduction in the sum of the products of the perpendicular diameters of all measurable disease and, if elevated, a $50 \%$ decrease of the CA-125 level for a minimum 4 weeks. Progression of disease after transplantation was defined as clinical or radiographic evidence of new, or progressive, disease or an increased CA-125 value. Platinum or paclitaxel resistant disease was defined as a disease that either did not respond to the platinum or paclitaxel-based therapy, or a disease that relapsed within 6 months of completion of the platinum or paclitaxel therapy.

\section{7) Statistical analysis}

The progression-free and overall survivals (PFS and OS) were measured from the date of the stem cell infusion. The 
Kaplan-Meier method was used for construction of survival curves.

\section{RESULTS}

\section{1) Patient characteristics}

The median age of the patients was 51 years, ranging from 40 to 62 . All patients presented with an advanced stage disease. Three patients were stage IV, 4 were stage IIIc, 2 were stage IIIb and 1 was stage IIIa. There were 9 patients with serous cystadenocarcinomas, and one patient with a mucinous cystadenocarcinoma. The residual disease was greater than $2 \mathrm{~cm}$ in all patients. The disease status before the high dose chemotherapy, were 5 each with primary or relapsed refractory (Table 1).

\section{2) Stem cell aphaeresis}

The stem cell collections were performed on two consequent days when the peripheral blood MNCs reached $1,000 / \mathrm{mm}^{3}$. There was no difference in efficacy of mobilization between the paclitaxel plus carboplatin, and the mini-ICE regimen. A median $10.25(3.1-26.6) \times 10^{6} \quad \mathrm{CD} 34+$ cells $/ \mathrm{kg}$ body weight was collected, and the median number of MNCs and CFU-GM colonies were $5.35(1.9-19.1) \times 10^{8} / \mathrm{kg}$ and 12 (range 0.19-

Table 1. Patient characteristics

\begin{tabular}{lc}
\hline \multicolumn{1}{c}{ Characteristics } & 10 \\
No. of patients & $51(40 \sim 62)$ \\
Median age (range) & \\
Histology & 9 \\
$\quad$ Serous cystadenocarcinoma & 1 \\
Mucinous cystadenocarcinoma & 1 \\
Stage at diagnosis & 2 \\
IIIa & 4 \\
IIIb & 3 \\
IIIc & \\
IV & 5 \\
Disease status before high dose chemotherapy & 5 \\
Primary refractory & \\
Relapsed refractory &
\end{tabular}

Table 2. Mobilization chemotherapy

\begin{tabular}{lc}
\hline Mobilization regimen & \multicolumn{2}{c}{6} \\
Taxol+carboplatin: & 6 \\
Mini-ICE: & \\
No. of collected PBSCs (median No.) \\
MNCs $\left(\times 10^{8} / \mathrm{kg}\right):$ & 5.35 (range $1.94 \sim 19.09)$ \\
CD34+cells $\left(\times 10^{6} / \mathrm{kg}\right):$ & 10.25 (range $3.10 \sim 26.64)$ \\
CFU-GM $\left(\times 10^{4} / \mathrm{kg}\right):$ & $12.0 \quad$ (range $0.19 \sim 114.10)$ \\
\hline
\end{tabular}

PBSCs: Peripheral blood stem cells, MNCs: Mononuclear cells
$114.1) \times 10^{4} / \mathrm{kg}$, respectively (Table 2 ).

\section{3) Hematopoietic recovery and toxicity after HDC with APBSCT}

After the HDC, all patients experienced severe marrow aplasia. The median time to attain a neutrophil count greater than $500 / \mathrm{mm}^{3}$, following the transplantation, was 9 days $(8 \sim$ 18 ), and to attain a platelet count greater than $20,000 / \mathrm{mm}^{3}$, was 14 days $(12 \sim 55)$ (Table 3). Eight patients developed neutropenic fevers, and bacteremia was documented in 4 ( 2 patients with Escherichia coli and 2 patients with Staphylococcus epidermidis). Any non-hematological toxicities were never life threatening. Eight patients had severe mucositis (more than WHO grade III) and 6 had hematuria (more than WHO grade II). One patient developed secondary myelodysplastic syndrome a year after HDC, so received an allogeneic bone marrow transplantation, and is still living without disease. There were no treatment related deaths (Table 4).

\section{4) Clinical outcome after HDC}

All ten patients were assessable for response. After mobilization chemotherapy, CR was achieved in 1/10 (10\%) and PR in $6 / 10(60 \%)$ patients. Following mobilized chemotherapy 5 out of the 6 partial responder achieved CR and 1 patient remained PR after HDC, resulting in an overall response rate of $70 \%$. Three patients who did not respond following mobilization chemotherapy also failed to achieve a response after high dose chemotherapy (Table 5). The median durations of PFS and OS were $6(4 \sim 46)$ and $13(3 \sim 50+)$ months, respectively. The median duration of OS of the responders following mobilization chemotherapy was $23(8 \sim 50+)$ months

Table 3. Conditioning chemotherapy

\begin{tabular}{lc}
\hline Regimen & \\
Carboplatin $500 \mathrm{mg} / \mathrm{m}^{2}$ & $\mathrm{D}-4-\mathrm{D}-2$ \\
Etoposide $700 \mathrm{mg} / \mathrm{m}^{2}$ & $\mathrm{D}-4-\mathrm{D}-2$ \\
Ifosfamide $3,300 \mathrm{mg} / \mathrm{m}^{2}$ & $\mathrm{D}-4-\mathrm{D}-2$ \\
Engraftment & \\
$\quad$ Median day of ANC $>500 / \mathrm{uL}$ (range) & $9(8 \sim 18)$ \\
$\quad$ Median day of platelet $>20,000 / \mathrm{uL}$ (range) & $14(12 \sim 55)$ \\
\hline \\
*ANC: absolute neutrophil counts
\end{tabular}

Table 4. Toxicities of high-dose chemotherapy

$\begin{array}{ll}\text { Complication } & \\ \text { Treatment related death } & 0 \\ \text { Fever } & 8 \\ \text { Documented infection } & 4 \\ \text { S.epidermidis } & 2 \\ \text { E.coli } & 2 \\ \text { Mucositis ( }>\text { Grade III) } & 8 \\ \text { Hematuria ( }>\text { Grade II) } & 6 \\ \text { Treatment related MDS } & 1\end{array}$

MDS: myelodysplastic syndrome 
Table 5. Clinical outcome

\begin{tabular}{rccccc}
\hline $\begin{array}{l}\text { No. of } \\
\text { Patient }\end{array}$ & $\begin{array}{c}\text { Disease } \\
\text { status }\end{array}$ & $\begin{array}{c}\text { Response to } \\
\text { mobilization } \\
\text { chemotherapy }\end{array}$ & $\begin{array}{c}\text { Response to } \\
\text { High-dose } \\
\text { chemotherapy }\end{array}$ & $\begin{array}{c}\text { Relapse-free } \\
\text { survival } \\
\text { (months) }\end{array}$ & $\begin{array}{c}\text { Overall } \\
\text { survival } \\
\text { (months) }\end{array}$ \\
\hline 1 & 1'R & CR & CR & 46 & $50+$ \\
2 & 1 'R & PR & PR & 4 & 8 \\
3 & 1 'R & PR & CR & 6 & $23+$ \\
4 & RR & NR & NR & 18 & \\
5 & RR & PR & CR & 45 & 45 \\
6 & RR & PR & CR & 6 & 9 \\
7 & 1 R & PR & CR & 6 & 9 \\
8 & RR & NR & NR & & 3 \\
9 & 1 R & NR & NR & & 12 \\
10 & RR & PR & CR & $30+$ & $30+$
\end{tabular}

1'R: primary refractory, RR: relapsed refractory, CR: complete response, PR: partial response, NR: No response.

compared with $12(3 \sim 18)$ months of the non-responders (Fig. 1).

\section{DISCUSSION}

Modern cytotoxic therapies, including platinum, paclitaxel and topotecan, have improved the median survival of patients with advanced ovarian cancer. The long-term results from these therapies are not available, but the progression-free period in patients with the suboptimally debulked disease is still less than 2 years (13). The initial retrospective dose intensity study of Levin and Hryniuk established the relationship between cisplatin dose intensity and outcome in patients with ovarian cancer (14). Clinical high-dose trials began in the late 1980s, targeting the refractory disease. The response rate was much higher than for conventional-dose regimens, and although the response was short, a few patients survived longer. Although no phase III trials evaluating its use are complete, substantial efforts to define patient groups who may benefit from this therapy has resulted in the opening of several phase III trials $(15 \sim 17)$. Our study assessed HDC and APBSCT in 10 patients with persistent or relapsed ovarian cancer. All the patients received 2 cycles of chemotherapy for mobilization and cytoreduction prior to the HDC. The response rate was $70 \%$, six patients having $\mathrm{CR}$ and one PR, with a duration of OS of $13(3-50+)$ months. There were no toxic deaths, and the non-hematologic toxicities were acceptable. Following after mobilized chemotherapy 5 out of the 6 partial responders achieved CR, but no patient showed a response after the HDC in the non-responders to mobilization chemotherapy. The overall survival of the responders was significantly longer than for the non-responders. Although the number of evaluated patients was small and the disease status heterogeneous, our data suggest the responders to cytoreductive mobilization chemotherapy achieved a higher response rate, and survived longer in primary or relapsed refractory patients with ovarian cancer. In a multicentered Gynecologic Oncology Group (GOG) trial (16), nine patients with recurred and refractory

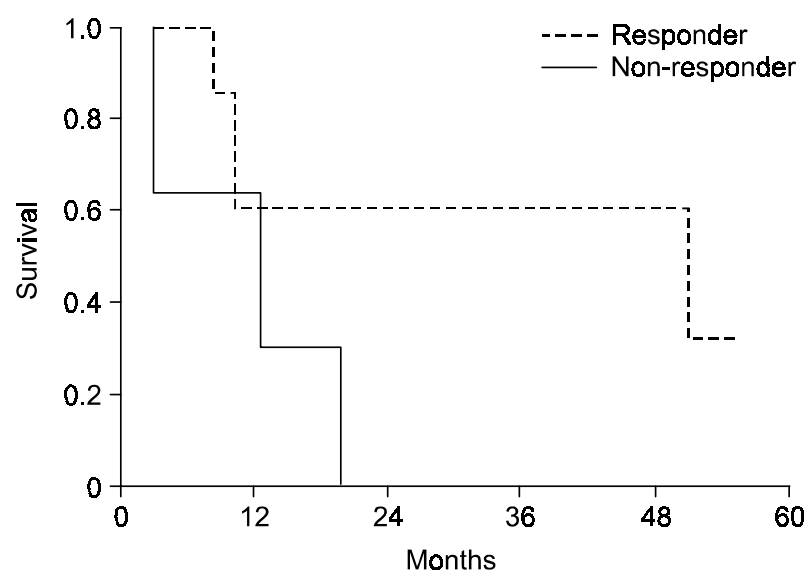

Fig. 1. Comparison of overall survival of the patients received HDC and APBSCT according to the response to salvage chemotherapy.

ovarian cancer were treated with HDC and autologous bone marrow support. Five patients had a clinical CR and one a PR lasting for 6 months. Shpall et al. treated 12 patients with HDC and stem cell support (15). The response rate was $75 \%$, with the response documented surgically. However, the remission duration was only 6 months. These data reveal, HDC and AHSCT for refractory/relapsed ovarian cancer, to have a higher response rate, but only short response duration. In several trials, including ours, occasional patients with chemorefractory disease survived longer with HDC and APBSCT. Recent studies have tried to find prognostic factors for patients with ovarian cancer receiving HDC and AHSCT $(18 \sim 20)$. The pretransplant prognostic variables evaluated in multivariate analyses were initial stage and grade, response to induction therapy, number of prior regimens, bulk and platinum sensitivity at transplant, age, time from diagnosis and transplant regimen $(21 \sim 24)$. The best prognostic group was considered to be patients who were both platinum sensitive, with a low tumor burden. In the absence of randomized data, there appears to be a survival advantage to transplant for the responding relapsed disease, perhaps in part due to more active salvage therapy following long remissions induced by the high dose therapies. The use of high-dose therapy at diagnosis should be investigated because of the rapid development of drug resistance in ovarian cancer. However, a significant proportion of these patients have the platinum-resistant disease, and for this reason an alternative strategy would be to perform transplantation, but only in the impressive responders to a brief course of initial conventionaldose chemotherapy (25).

\section{CONCLUSIONS}

HDC, followed by APBSCT, was well tolerated in patients with refractory or relapsed ovarian cancer. Although the number of evaluated patients was small and the disease status heterogeneous, our data suggest the responders to cytoreductive mobilization chemotherapy achieved a higher response rate and survived longer in primary or relapsed refractory patients with 
ovarian cancer.

\section{REFERENCES}

1. Jemel A, Thomas A, Murray T, Thun M. Cancer statistics, 2002. CA Cancer J Clin 2002;52:23-47.

2. Bae JM, Won YJ, Jung KW, Suh KE, Ahn DH, Park JG. Annual report of the central cancer registry in Korea: based on registered data from 128 hospitals. Cancer Res Treat 2001;33:367-372.

3. McGuire WP, Hoskins WJ, Brady MF, Kucera PR, Partridge EE, Look KY, Clarke-Pearson DL, Davidson M. Cyclophosphamide and cisplatin compared with paclitaxel and cisplatin in patients with stage III and stage IV ovarian cancer. N Engl J Med 1996;334:1-6.

4. Ozols RF, Young RC. Chemotherapy of ovarian cancer. Semin Oncol 1991;18:222-232.

5. Bertucci F, Viens P, Delpero JR, Bardou VJ, Faucher C, Houvenaeghel G, Maraninchi D. High-dose melphalanbased chemotherapy and autologous stem cell transplantation after second look laparotomy in patients with chemosensitive advanced ovarian carcinoma: long-term results. Bone Marrow Transplant 2000;26:61-67.

6. McGuire WP. Highdose chemotherapeutic approachs to ovarian cancer management. Smin Oncol 2000;27(Suppl 7):41-46.

7. Fennelly D, Schneider J. Role of chemotherapy dose intensification in the treatment of advanced ovarian cancer. Oncology (Huntingt) 1995;9:911-921.

8. Viens P, Maraninchi D, Legros M, Oberling F, Philip T, Herve P, Plagne R, Dufour P, Bergerat JP, Guastalla JP. High-dose melphalan and autologous marrow rescue in advanced epithelial ovarian carcinomas: a retrospective analysis of 35 patients treated in France. Bone Marrow Transplant 1990;54: 227-233.

9. Stiff PJ, McKenzie RS, Alberts DS, Sosman JA, Dolan JR, Rad N, McCloskey T. Phase I clinical and pharmacokinetic study of high-dose mitoxantrone combined with carboplatin, cyclophosphamide, and autologous bone marrow rescue: high response rate of refractory ovarian carcinoma. J Clin Oncol 1994;12:176-183.

10. Ellis ED, Williams SF, Moormeier JA, Kaminer LS, Bitran JD. A phase I-II study of high-dose cyclophosphamide, thiotepa and escalating doses of mitoxantrone with autopogous stem cell rescue in patients with refractory malignancies. Bone Marrow Transplant 1990;6:439-442.

11. Legros M, Dauplat J, Fleury J, Cure H, Suzanne F, Chassagne J, Bay JO, Sol C, Canis M, Condat P, Choufi B, Tavernier F, Glenat C, Chollet P, Plagne R. High-dose chemotherapy with hematopoetic rescue in patients with stage III to IV ovarian cancer: long-term results. J Clin Oncol 1997;15:13021308.

12. Lee JM, Cho SG, Park JN, Hong YS, Kim HK, Namkoong SE, Lee KS, Kim CC. A case of triple-alkylating regimen and peripheral blood stem cell transplantation or a patient with relapsed ovarian carcinoma. J Korean Cancer Assoc 2000;32: 817-821.

13. Stuart G, Bertelson K, Mangioni C. Updated analysis shows a highly significant improvement in overall survival (OS) for cisplatin-paclitaxel as first line treatment of advanced ovarian cancer: Mature results of the EORTCGCCG, NOCOVA, NCIC \& Scottish Intergroup trial. Proc Am Clin Oncol 1998; 17:361a.

14. Levin L, Hryniuk W. Dose intensity analysis of chemotherapy regimens in ovarian carcinoma. J Clin Oncol 1987;5:756-767.

15. Shpall EJ, Clarke-Pearson D, Soper JT, Berchuck A, Jones RB, Bast RC Jr, Ross M, Lidor Y, Vanacek K, Tyler T. High-dose alkylating agent chemotherapy with autologous bone marrow support in patients with stage III/IV epithelial ovarian cancer. Gynecol Oncol 1990;38:386-391.

16. Broun ER, Belinson JL, Berek JS, McIntosh D, Hurd D, Ball $\mathrm{H}$, Williams S. Salvage therapy for recurrent and refractory ovarian cancer with high-dose chemotherapy and autologous bone marrow support: a Gynecologic Oncology Group pilot study. Gynecol Oncol 1994;54:142-146.

17. Aghajanian C, Fennelly D, Shapiro F, Waltzman R, Almadrones L, O'Flaherty C, O'Conner K, Venkatraman E, Barakat R, Curtin J, Brown C, Reich L, Wuest D, Norton L, Hoskins W, Spriggs DR. Phase II study of dose-dense high-dose chemotherapy with peripheral blood progenitor cell support as primary treatment for patients with advanced ovarian cancer. J Clin Oncol 1998;16:1852-1860.

18. Cure H, Extra JM, Viens P. High dose chemotherapy with hematopoetic stem cell support as consolidation therapy for patients with platinum-sensitive advanced epithelial ovarian cancer. Proceedings of the Fourth International Symposium on High-dose Chemotherapy and Stem Cell Transplant in Solid Tumors. Berlin;1998.

19. Stiff PJ, Veum-Stone J, Lazarus HM, Ayash L, Edwards JR, Keating A, Klein JP, Oblon DJ, Shea TC, Thome S, Horowitz MM. High-dose chemotherapy and autologous stem-cell transplantation for ovarian cancer: an autologous blood and marrow transplant registry report. Ann Intern Med 2000;133:504-515.

20. Cure H, Battista C, Guastalla JP. Phase III randomized trial of high-dose chemotherapy(HDC) and peripheral blood stem cell (PBSC) support as consolidation in patients(pts) with responsive low-burden advanced ovarian cancer (AOC): preliminary results of a GINECO/FNCLCC/SFGM-TC study. Proc Am Soc Clin Oncol 2001:815a.

21. Pujade-Lauraine E, Cure H, Battista C, Guastalla JP, Chiurazzi B, Fabbro M, Tubiana-Mathieu N, Bourgeois H, Lioure B, Paraiso D, Lotz JP. High dose chemotherapy in ovarian cancer. Int J Gynecol Cancer 2001;11(Suppl 1):64-67.

22. Salerno MG, Ferrandina G, Greggi S, Pierelli L, Menichella G, Leone G, Scambia G, Mancuso S. High-dose chemotherapy as a consolidation approach in advanced ovarian cancer: longterm results. Bone Marrow Transplant 2001;27:1017-1025.

23. Holmberg LA, Demirer T, Rowley S, Buckner CD, Goodman G, Maziarz R, Klarnet J, Zuckerman N, Harrer G, McCloskey R, Gersh R, Goldberg R, Nichols W, Jacobs A, Weiden P, Montgomery P, Rivkin S, Appelbaum FR, Bensinger WI. Highdose busulfan, melphalan and thiotepa followed by autologous peripheral blood stem cell (PBSC) rescue in patients with advanced stage III/IV ovarian cancer. Bone Marrow Transplant 1998;22:651-657.

24. Stiff PJ, Bayer R, Kerger C, Potkul RK, Malhotra D, Peace DJ, Smith D, Fisher SG. High-dose chemotherapy with autologous transplantation for persistent/replapsed ovarian cancer: a multivariate analysis of survival for 100 consecutively treated patients. J Clin Oncol 1997;15:1309-1317.

25. Stiff PJ. High dose therapy and stem cell transplantation for ovarian cancer. In: Armitage JO, Antman KH, eds. High-dose cancer therapy: Pharmacology, Hematopoietins, Stem cells. 3rd ed. Philadelphia: Lippincott, 2000:853-869. 